\title{
Reumatismo indiferenciado y/o ventoseo comicial
}

\author{
R. VEIGA CABELLO, J. R. TORAL REVUELTA, E. SÁNCHEZ SÁNCHEZ', \\ J. FERNÁNDEZ ÁLVARO, J. DE D. SÁEZ GARRIDO ${ }^{2}$ \\ Servicios de Reumatología, Medicina Interna, ${ }^{1}$ Aparato Digestivo ${ }^{2}$ Oncología \\ Radioterápica. Hospital del Aire y ${ }^{2}$ Hospital Gómez Ulla. Madrid
}

INDIFFERENTIATED RHEUMATISM AND/OR EPILEPTIC FLATULENCE

\section{RESUMEN}

Se presenta el caso de una mujer de 50 años, remitida a la consulta de Reumatología para estudio de un síndrome seco clínico con una alteración inmunitaria (aún no definida), que desarrolla tumores (de momento benignos) y autoinmunidad analítica de tipo antitopoisomerasa 1 (anti Scl-70) confirmado. Se comenta el caso clínico y se discuten las causas de su meteorismo, entre ellas una posible variante de epilepsia abdominal como ventoseo comicial, secundario a un meningioma de la convexidad cerebral derecha.

PALABRAS CLAVE: Autoinmunidad. Epilepsia abdominal. Meteorismo.
A clinical case study of a 50 year-old woman brought to the Rhematology Department is presented, who showed clinical dry syndrome with immune disorders (not currently defined) and developed tumors (benign at present) and analytical autoimmunity with positive antitopoisomerase type I (formerly Scl70) confirmed. The clinical case is commented and the metheorism causes are discussed, among it, a possible variation of abdominal epilepsy as ictal flatulence, secondary to a meningioma of the right brain convexity.

KEY WORDS: Autoimmunity. Abdominal epilepsy. Flatulence.

\section{ABSTRACT}

Veiga Cabello R, Toral Revuelta JR, Sánchez, Sánchez E, Fernández Álvaro J, Sáez, Garrido J de D. Reumatismo indiferenciado y/o ventoseo comicial. An Med Interna (Madrid) 2003; 20: 367-369.

\section{INTRODUCCIÓN}

Es de todos conocido que ciertos rasgos clínicos, tales como fenómeno de Raynaud, poliartritis, neumonitis intersticial, pleuritis, pericarditis o vasculitis no etiquetan por sí solos una enfermedad reumática. No es raro encontrar pacientes que impresionan de proceso reumático indiferenciado que ni siquiera tienen uno de esos rasgos, incluso en los que no puede hablarse de reumatismo a pesar de tener artralgias y que impresionan de proceso autoinmune no diferenciado. Por otro lado, diariamente muchas células mueren y son reemplazadas por otras genéticamente idénticas, en un proceso que conlleva múltiples mutaciones al azar o por influencia de agentes externos. Según la teoría de la "vigilancia inmunológica", una de las principales misiones del sistema inmunitario es evitar que una célula transformada evolucione a un clon tumoral. Se puede suponer en un paciente una alteración inmunitaria que al no reconocer las células tumorales como antigénicas favorezca el desarrollo de tumores, y que al no reconocer las estructuras propias desarrolle autoinmunidad.

\section{CASO APORTADO}

Mujer de 50 años, natural de Hungría, madre de un hijo por cesárea de entre tres embarazos, con una abigarrada patología psiquiátrica desde la década de los 80, etiquetada de depresión paranoide, que motivó varios ingresos, controlada actualmente con olanzapina, hidroxicina diclorhidrato, y sulpiride. En 1989, tras resección de las tres cuartas partes corpocaudales, se diagnosticó de cistoadenoma mucoso de páncreas. En 1996 se realizó histerectomía y doble anexectomía por fibroleiomioma múltiple y pólipo endocervical. En 1997 se practicó hemitiroidectomía derecha y extirpación de sendos nódulos mamarios (adenoma folicular de tiroides y displasia fibroquística). Desde entonces presentaba episodios de estreñimiento (1 deposición/4-5 días) de 2-3 semanas seguidos de diarrea (8-10 deposiciones/día) de 2-3 días, así como meteorismo con distensión abdominal y síndrome seco. En la exploración física completa destacaba la xerostomía y un aumento del perímetro abdominal por acusado timpanismo, siendo el resto normal.

En el estudio del proceso diarreico y el síndrome seco, se objetivó leucopenia de 4000/ul con fórmula normal, trombopenia de 140.000/ul, VSG de $24 \mathrm{~mm}$, glucosuria, ferropenia de $35 \mathrm{ug} / \mathrm{ml}$ con

Trabajo aceptado: 24 de octubre de 2002

Correspondencia: Raúl Veiga Cabello. $\mathrm{P}^{\mathrm{o}}$ de la Chopera, 101, 3º B, 28100 Alcobendas (Madrid). 
índice de saturación del 7,4\%, anticuerpos antitopoisomerasa 1 positivos, dos pólipos vellosos rectales (hiperplásicos) en la colonoscopia, y esteatosis hepática en la ecografía abdominal. Resultaron normales o negativos el resto de la bioquímica, orina, vitamina B12, ácido fólico, hormonas tiroideas, autoanticuerpos (antinucleares, anti-ADN, SM, SSA y SSB; antimitocondriales, antimúsculo liso; anti LKM, gliadina, endomisio, y Jo-1), serologías (VHC, VHB, VIH), coprocultivo, digestión en heces, así como la endoscopia digestiva alta y el tránsito intestinal con bario. Se inició tratamiento con enzimas pancreáticas, dieta antiflatulenta, metronidazol y mebeverina, sin obtener mejoría, y se consultó a los Servicios de Psiquiatría y Reumatología.

Como datos de interés reumatológico, refería dos abortos (estudio de coagulación y cardiolipinas negativas), síndrome seco clínico de ojos, boca (confirmado por sialografía) y vagina, dolor de interfalángicas proximales con un dudoso episodio de aumento de volumen en codo izquierdo (factor reumatoide y PCR negativos, con radiografías normales), y disnea de esfuerzo (TLCO 68\%, radiografía de tórax y ECG normales). Un nuevo estudio analítico confirmó los hallazgos referidos y reveló una hiperglucemia de $200 \mathrm{mg} / \mathrm{dl}$. Se diagnosticó de diabetes tipo II y se inició tratamiento con dieta, ejercicio y glipizida, mejorando su estado metabólico. En 1998 acudió a revisión al Servicio de Reumatología, con la frase de "Doctor, tengo un tumor en la cabeza". Al inquirir acerca de cómo y quién le realizó ese diagnóstico, contestó que leyendo una revista encontró analogía entre dos pacientes que durante años estaban siendo diagnosticados y tratados de depresión por ataques de risa y por orgasmos múltiples no esperados (hasta ser intervenidos y curados de un proceso expansivo intracraneal), con su meteorismo y flatulencia severas, que motivaron las quejas por ruido de su vecino de abajo, la pérdida y cambio de empleo y el aislamiento social. Al pedirle una demostración del ventoseo, respondió que no "estaba en fase". Según la paciente, durante la fase de estreñimiento, acumulaba de forma progresiva los gases hasta que cíclicamente, a las dos o tres semanas y durante dos o tres días, de forma no controlada, presentaba un ventoseo explosivo con sensación de urgencia deposicional, y anestesia

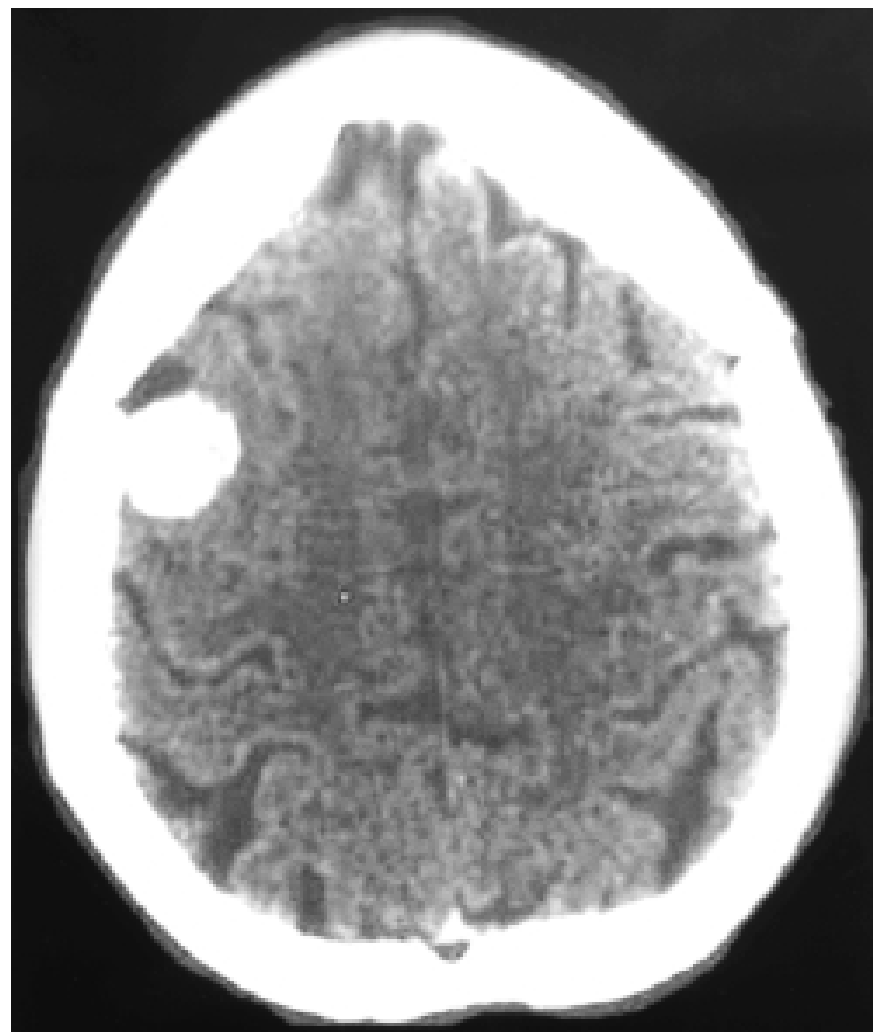

Fig. 1. Imagen TAC del meningioma temporal derecho. discriminativa de recto. "No tengo eructos ni dolor abdominal, me lleno de heridas en el ano, y mi psiquiatra no se lo explica". Su hijo en una consulta posterior confirma la historia clínica, y describe el ventoseo como la "explosión de un neumático". Se realiza un TAC craneal, que mostraba un nódulo de $2 \mathrm{~cm}$ de alta densidad en la convexidad cerebral derecha, pegado a la tabla interna (Fig. 1), y un E.E.G., con lentificación del trazado temporal derecho (Fig. 2). Tras craneotomía, se diagnosticó de meningioma, y se asoció al tratamiento ácido valproico. Tras la cirugía del meningioma se obtiene una mejoría espectacular de las manifestaciones digestivas durante los dos o tres primeros meses, para de forma progresiva volver la flatulencia con un ventoseo diario y no explosivo. Desde enero de 2000, se ajustó la alimentación a una dieta sin gluten, con lo que se objetiva una disminución del meteorismo.

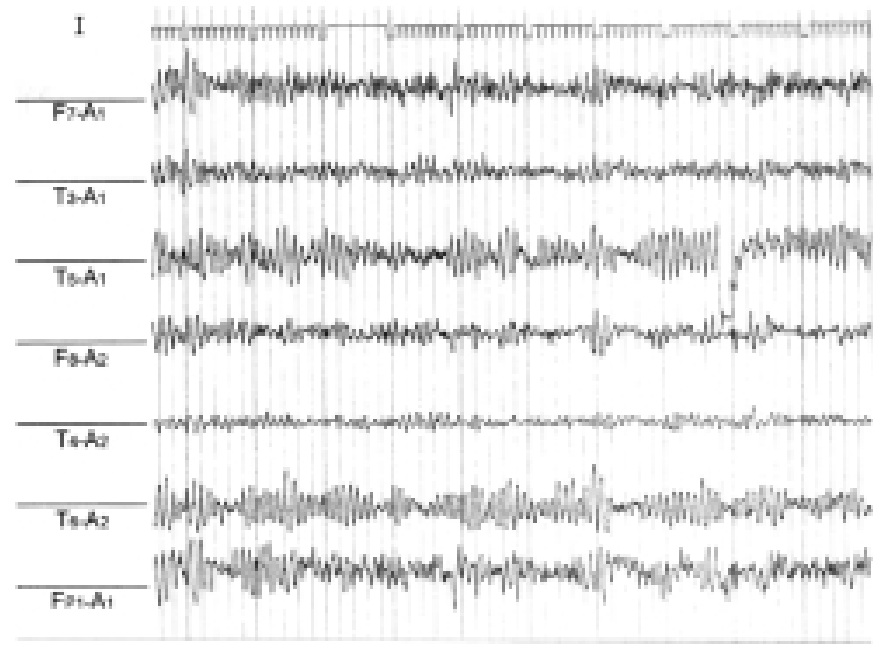

Fig. 2. Lentificación EEG del trazado temporal derecho.

\section{DISCUSIÓN}

Entre los diagnósticos compatibles con el cuadro clínico, tendríamos un posible reumatismo autoinmune. La positividad del autoanticuerpo antitopoisomerasa 1 sugiere una esclerosis sistémica progresiva, en este caso la variedad sine escleroderma, ya que no hay afectación cutánea de momento. Apoyan este diagnóstico las artralgias difusas de interfalángicas proximales de manos y la dudosa inflamación de codo izquierdo, el síndrome seco, las citopenias, la difusión gaseosa reducida (que pudiera traducir una neumopatía intersticial asociada), y las diarreas alternas con estreñimiento y el meteorismo (que pudieran deberse a una hipomotilidad de intestino delgado con sobrecrecimiento bacteriano, diarrea y episodios intermitentes de distensión abdominal, y a una hipomotilidad de colon, con estreñimiento e incontinencia rectal). La nula progresión clínica, y la falta de datos típicos como el endurecimiento cutáneo y el fenómeno de Raynaud, hacen improbable este diagnóstico, y hacen pensar que el autoanticuerpo antitopoisomerasa 1 debe tenerse más como marcador de autoinmunidad, que como diferenciador de un cuadro clínico. La enfermedad celiaca es una enfermedad autoinmune que puede asociarse a otros procesos autoinmunes (1) como la diabetes insulino-dependiente (2) y que en el caso de la paciente podría explicar la anemia ferropénica, el meteorismo y la alte- 
ración del ritmo intestinal, aunque su diabetes es de tipo II. Sin embargo, el proceso expansivo intracraneal era un meningioma y no una calcificación (3-4), y los autoanticuerpos antigliadina y antiendomisio eran negativos (5). Otra posibilidad sería las bridas postquirúrgicas en un abdomen multioperado, que originasen cuadros de suboclusión, la patología intestinal funcional como el colon irritable, y la afectación intestinal de la diabetes (6), por neuropatía autonómica (7) o un déficit enzimático pancreático asociado. La breve evolución de la diabetes, la falta de malabsorción y de respuesta a las enzimas pancreáticas o antibióticos orales, hacen improbable el diagnóstico.

La epilepsia abdominal fue descrita por Trousseau en 1868 (8). Desde entonces existen pocos casos en la literatura, como vómitos cíclicos, naúseas, eructos, dolor abdominal, o diarrea (9-14). No se ha encontrado ningún caso de ventoseo comicial en la base de datos Medline entre 1966 y 2002. En 1971 Douglas estableció como criterios de epilepsia abdominal el dolor abdominal paroxístico y cíclico de duración variable, las alteraciones de la conciencia, el síndrome postictal, las anomalías E.E.G., y la mejoría con la medicación antiepiléptica (9). En 1983 Wendy corrigió estos criterios, sugiriendo que no son imprescindibles las alteraciones de la conciencia o el síndrome postictal (11). La paciente presentaba ventoseo paroxístico y cíclico, sin dolor abdominal, alteraciones de la conciencia, síndrome postictal, ni alteraciones E.E.G., excepto la lentificación del trazado temporal derecho, y con cambio de la flatulencia tras la cirugía del meningioma y el tratamiento anticomicial. La paciente no fue sometida a estudios E.E.G. con electrodos profundos o en las crisis de ventoseo (15), aunque la lentificación del trazado temporal derecho, en la suposición de existir un foco epileptógeno, sugiere que estaría en el lóbulo temporal derecho, posiblemente en las proximidades del área motora suplementaria, que es la responsable en modelos animales de las respuestas autonómicas (16).

En resumen, la paciente presenta una alteración inmunitaria, que puede predisponer a tumores, de momento benignos, y a un proceso autoinmune con positividad del anticuerpo antitopoisomerasa 1, que sugiere enfermedad autoimune no diferenciada en el momento actual. ¿Hay un aumento en la producción intraluminal de gas por diabetes, insuficiencia pancreática o sobrecrecimiento bacteriano?...o ¿hay un aumento de la ingesta de gas por el síndrome ansioso-depresivo, raro sin eructos? (17). Gas que se expulsaría de forma violenta y con heces diarreicas sin discernimiento ano-rectal, ya por un colon irritable, ya por un ventoseo comicial. Si suponemos una causa epiléptica, se explicaría por descargas autonómicas cíclicas de un foco vecino al área motora suplementaria derecha, con espasmo intestinal y progresión distal y salida explosiva del gas, arrastrando heces que no han tenido tiempo de compactarse en el colon, con sensación de urgencia deposicional. La incontinencia rectal, con poca discriminación del paso gasheces, se debería a un fallo del esfinter anal interno, de inervación autonómica, frente al externo que es voluntario (18).

\section{Bibliografía}

1. Copper BT, Holmes GKT, Cooke WT. Coeliac disease and immunological disorders. BMJ 1978; 1: 537-42.

2. Barrera G, Bianchi C, Calisti L, et al. Screening of diabetic children for coeliac disease with antigliadin antibodies and HLA typing. Arch Dis Child 1991; 66: 491-94.

3. Gobbi G, Zaniboni M, et al. Coeliac disease, epilepsy, and cerebral calcifications. Lancet 1992; 340: 439-43.

4. Baquero M, Narciso M. Celiaquía con calcificaciones occipitales: dos casos tardíos. Med Clin (Barc) 1995; 781-783.

5. Bürgin-Wolf A, Gaze H, et al. Antigliadin and antiendomysium antibody determination for celiac disease. Arch Dis Child 1991; 66: 941-47.

6. Feldman M, Schiller L. Disorders of gastrointestinal motility associated with diabetes mellitus. Ann Intern Med 1983; 98: 378-384.

7. Adan FM, Marta J, Marta E, Jimeno A, Martínez-Berganza A, Cia P. Manifestaciones poco frecuentes de la neuropatía diabética. An Med Interna (Madrid) 1992; 9: 291-293.

8. Wallis HRE. Masked epilepsy. Lancet 1995;1:70.

9. Douglas E, White P. Abdominal epilepsy -a reappraisal. J Pediat 1971; 78: 59-67.

10. Jacome D, Fitzgerald R. Ictus emeticus. Neurology 1982; 32: 209-12.

11. Wendy G, Messenheirmer J. Abdominal epilepsy. Cyclic vomiting as

the major symptom of simple partial seizures. Arch Neurol 1983; 40: 251-252.

12. Schauble B, Britton JW, Mullan BP, Watson J, Sharbrough FW, Marsh WR. Ictal vomiting in association with left temporal lobe seizures in a left hemisphere language-dominant patient. Epilepsia 2002; 43: 14321435 .

13. Baumgartner C, Lurger S, Leutmezer F. Autonomic symptoms during epileptic seizures. Epileptic Disord 2001; 3:103-116.

14. Chen C, Yen DJ, Yiu CH, Shih YH, Yu HY, Su MS. Ictal vomiting in partial seizures of temporal lobe origin. Eur Neurol 1999; 42:235239.

15. Morris H, Turnbull J, et al. Chronic intractable epilepsy as the only symptom of primary brain tumor. Epilepsia 1993; 34 (6): 1038-1043.

16. Penfield W, Welch K. The supplementary motor area of the cerebral cortex: a clinical and experimental study. Arch Neurol Psychiatry 1951; 66: 289-317.

17. Dobrilla G, Amplatz S. Planteamiento dietético en los pacientes con dispepsia funcional. An Med Interna (Madrid) 1987; 4: 89-96.

18. Schiller LR, Fordtran JS, et al. Pathogenesis of fecal incontinence in diabetes mellitus: evidence for internal anal sphincter dysfunction. $\mathrm{N}$ Engl J Med 1982; 307: 1666-71. 